\title{
Dispositivo de medição de deslocamentos em via permanente para determinação do módulo de via
}

\author{
Robson Costa ${ }^{1}$, Edson Moura ${ }^{2}$, Liedi Bernucci ${ }^{3}$, Rosângela Motta ${ }^{4}$, Arthur Teixeira $^{5}$ e Luciano de Oliveira ${ }^{6}$
}

\begin{abstract}
Resumo: Um parâmetro usado como indicador da resposta elástica e qualidade da via permanente em diversas ferrovias é o módulo de via (u), o qual requer a determinação de deslocamentos (deflexões) em campo. O presente trabalho tem o objetivo de apresentar um dispositivo para medição de deslocamentos (DMD), desenvolvido para registrar deflexões durante a passagem dos trens sem interrupção da operação da ferrovia. Para demonstrar sua viabilidade, o DMD foi usado em medições de dois segmentos da Estrada de Ferro Carajás (EFC), com diferentes condições de lastro e dormente. Os resultados apontaram que o dispositivo se mostrou apropriado para realizar as medições de deslocamentos, que posteriormente são usadas no cálculo do módulo de via. Adicionalmente, no estudo de caso foi possível observar que a forma de carregamento (função da velocidade) implica em respostas mecânicas diferentes, e que a medida de deslocamentos efetuada no patim do trilho é mais adequada. Ademais, observou-se que o dispositivo também pode eventualmente ser capaz de indicar um possível defeito na roda ou no trilho. De modo geral, concluiu-se que o DMD pode ser uma ferramenta útil para auxiliar a gerência de manutenção de uma ferrovia.
\end{abstract}

Palavras-chave: lastro, módulo de via, via permanente.

\begin{abstract}
A parameter used as an indication of elastic response and quality in several railroads is the track modulus (u), which requires the determination of displacements (deflections) in the field. This paper aims to present a Device for Measurements of Displacements (DMD), developed to register deflections during the passage of trains without interrupting the railroad operation. To demonstrate its feasibility, the DMD was used in measurements of two sections in Estrada de Ferro Carajás (EFC), with different conditions of ballast and sleeper. The results showed that the device proved to be suitable for performing the measurement of displacements, which are subsequently used in calculating the track modulus. Additionally, in the case study it was observed that the way of loading (function of speed) relies on different mechanical responses and that measurement on the foot of the rail is more appropriate. Furthermore, it was observed that the device may likely indicate a possible defect in the wheel or in the rail. In general, it was found that the DMD can be a useful tool to help on the railroad maintenance management.
\end{abstract}

Keywords: ballast, track modulus, railway.

\section{INTRODUÇÃO}

A crescente demanda no escoamento de matérias primas, materiais ou grãos tem exigido do modal ferroviário um aumento no volume da carga a ser transportada em um menor intervalo de tempo. Isto gera um maior número de solicitações em todos os componentes da superestrutura e subestrutura da via permanente, ocasionando elevados níveis de tensões verticais, transversais e longitudinais. Dentre os componentes, a camada de lastro é muito suscetível a sofrer alterações de seu próprio material e, por consequência, de sua resposta mecânica. Tais mudanças podem ocorrer devido às ações de intempéries, bem como de elevadas tensões provocadas pelo carregamento dinâmico, fazendo

\footnotetext{
1 Robson Costa, Departamento de Engenharia de Transportes, USP. (robsoncosta@usp.br)

2 Edson Moura, Departamento de Engenharia de Transportes, USP. (edmoura@usp.br)

${ }^{3}$ Liedi Bernucci, Departamento de Engenharia de Transportes, USP. (liedi@usp.br)

${ }^{4}$ Rosângela Motta, Departamento de Engenharia de Transportes, USP.

(rosangela.motta@usp.br)

${ }^{5}$ Arthur Teixeira, Departamento de Engenharia de Transportes, USP.

(arthur.mattar.teixeira@usp.br)

${ }^{6}$ Luciano de Oliveira, Departamento de Engenharia, Vale S.A.

(oliveira.luciano@vale.com)
}

Manuscrito recebido em 20/04/2016 e aprovado para publicação em $15 / 07 / 2016$

Este artigo é parte de TRANSPORTES v. 24, n. 4, 2016. ISSN: 2237-1346 (online). DOI:10.14295/transportes.v24i4.1140 com que os agregados se desgastem por abrasão e/ou quebra.

A presença de partículas finas no lastro (menores que 9,5 $\mathrm{mm}$ para Selig e Waters (1994) e que 22,5 mm para Esveld (2001)) é indesejável, uma vez que contribui para sua colmatação. A propósito, cabe mencionar que os finos não somente podem advir de desgaste ou quebra de agregados, mas também de fontes externas ao lastro, seja de queda de material transportado (por exemplo, minério de ferro), seja de bombeamento de finos do sublastro/subleito, tendo-se nestes casos uma situação denominada de contaminação.

O material indesejado altera a curva granulométrica, diminui a capacidade de drenagem e pode modificar a resposta resiliente do lastro (variando de acordo com o tipo de fino entre as partículas, seja na condição seca ou úmida), podendo contribuir para mudanças no comportamento mecânico da estrutura da via permanente.

Um parâmetro que tem sido usado em diversas ferrovias do mundo como indicador da resposta elástica (SELIG e LI, 1994; PRIEST e POWRIE, 2009; ZAKERI e ABBASI, 2012) e da qualidade da ferrovia, é o módulo de via $(u)$. Estudos coordenados por Talbot (AMERICAN RAILWAY ENGINEERING ASSOCIATION - AREA, 1918), quanto à análise de tensões na via permanente, introduziram o conceito de módulo de via $(u)$, definindo-o como uma força pelo comprimento unitário que cada trilho requer para provocar uma deflexão unitária (deslocamento vertical) na via. 
O módulo de via pode ser um modelo de previsão de desempenho da via permanente, pois através do mesmo é possível analisar a interação entre os componentes abaixo do trilho atuando de maneira conjunta, em função do carregamento e deslocamento ocasionados pelo material rodante (SELIG e WATERS, 1994).

Muitos fatores podem influenciar no valor do módulo de via. Não há um consenso entre autores, mas entre os mais significativos têm-se: tipo e dimensões do dormente; material, espessura e capacidade de suporte do lastro; e tipo e capacidade de suporte do subleito (LUNDGREN, MARTIN e HAY, 1970). Nos estudos computacionais realizados por Selig e Li (1994), por exemplo, concluiu-se que o fator que mais influência no módulo de via (ou de rigidez) é a condição do subleito (representado por seu módulo de resiliência). Enquanto que Cai, Raymond e Bathurst (1994), demonstraram através de exemplos numéricos que o módulo de via aumenta de maneira mais significativa com o dormente de concreto ao se elevar a rigidez do lastro/subleito, em comparação com uma via com dormente de madeira.

Outro aspecto se refere à análise de tensões e de comportamento mecânico da via permanente, por meio do módulo de via, conforme descrito mais adiante no item 2. Diversos pesquisadores (SELIG e WATERS, 1994; MUNIZ DA SILVA, 2002; ANDERSON e ROSE, 2008; PRIEST e POWRIE, 2009; ZAKERI e ABBASI, 2012) realizaram testes, entretanto, cada estudo tem condição e parâmetros de via particularizada como: tipo de material rodante, carga aplicada e velocidade empregada; uso de diferentes dispositivos na medição de deslocamento vertical, com posicionamento de sensores em locais distintos (alguns no patim do trilho, outros na borda do dormente, por exemplo); e metodologia específica de cálculo do módulo de via.

O presente trabalho tem o objetivo de apresentar um dispositivo de medição de deslocamentos (DMD) in situ, que foi desenvolvido para registrar tais deslocamentos ocasionados pela passagem do material rodante sem necessidade de interrupção da operação (situação dinâmica), cujos dados podem, posteriormente, ser usados no cálculo do módulo de via $(u)$. Neste caso, a utilização de um equipamento para medir deslocamentos em qualquer segmento da ferrovia, mantendo sua trafegabilidade normal, pode ser uma ferramenta útil para a gerência de manutenção ferroviária.

Nesse estudo considerou-se deslocamentos verticais, com o carregamento sendo feito com os trens em menor e maior velocidade. Para demonstrar a viabilidade do DMD, este foi usado em medições realizadas em dois segmentos da Estrada de Ferro Carajás (EFC), operada pela Vale, em diferentes condições de lastro (novo e colmatado) e de dormente (concreto e madeira). Além disso, levando-se em conta ainda que o tipo e a frequência de carregamento em que a via permanente é solicitada pode implicar em alterações na resposta mecânica de todos os componentes, foram realizados testes na via com vagões vazios e carregados a saber: i) teste com o trem em menor velocidade sobre lastro colmatado; ii) teste com o trem em operação normal também sobre lastro colmatado; e iii) teste em operação normal sobre lastro novo.

\section{TESTES REALIZADOS EM DIFERENTES ESTUDOS}

Os primeiros estudos referentes à análise de tensões na via permanente por carregamento estático e dinâmico foram coordenados por Talbot (AREA, 1918). O trecho de campo usado durante os testes se situava na estrada de ferro central de Illinois (Estados Unidos), onde se determinou segmentos homogêneos da via. Para tanto, preparou-se quatro trechos, a uma pequena distância um do outro, com diferentes espessuras de lastro (uma com $0,15 \mathrm{~m}$, uma com $0,60 \mathrm{~m}$ e duas com $0,30 \mathrm{~m}$ ). As medições de deslocamentos (deflexões) foram feitas a partir da base do trilho, sendo realizadas com uso de uma câmera posicionada a 10 pés $(3,048 \mathrm{~m})$, pois a essa distância a vibração da câmera já seria muito pequena e não afetaria os resultados das medições, exceto em alta velocidade. Considerou-se, então, que o movimento vertical do trilho era produzido pela flexão do mesmo e pelo movimento vertical do dormente, lastro e fundação.

Segundo Talbot (AREA, 1918), mesmo que uma via esteja bem conservada, haverá deflexões entre o trilho e a placa de apoio, entre esta e o dormente, e entre esse último e o lastro, em virtude da existência de um "gap" (espaço vazio entre a base do dormente e o topo do lastro), cujos valores variam entre $0,254 \mathrm{~mm}$ a $25,4 \mathrm{~mm}$, ou mais, o que já não é ideal, uma vez que na via permanente se deve manter um equilíbrio entre rigidez e elasticidade. Deste modo, recomendou-se que para uma linha principal em condições normais, o valor médio de deflexão deve ser de 1,63 mm.

Em um segmento de via construído em laboratório, Zarembski e Choros (1979) realizaram testes para medir as deflexões da via em três diferentes locais usando LVDTs (linear variable displacement transducers). Avaliaram três diferentes métodos de cálculo do módulo de via vertical usando: (A) bacia de deflexão; (B) bacia de deflexão gerada pela carga da roda de veículo carregado e descarregado; e (C) viga contínua sobre apoio elástico. Como resultado, os autores recomendaram o uso do método $\mathrm{C}$ para cálculo, pois o mesmo é determinado usando o nível de carga correspondente ao tráfego da ferrovia, diferentemente dos outros dois métodos.

Já Kerr (1983) propôs um método para determinação do módulo de via usando uma locomotiva ou um veículo de cargas múltiplas, embora Selig e Waters (1994) tenham apontado desvantagens desse método, pois o mesmo faz referência à deflexão gerada pelo veículo vazio e carregado, incorporando o "gap" entre essas deflexões.

Anderson e Rose (2008) realizaram estudos, com medidas de tensões e deflexões no trilho em duas linhas (a primeira entre Cincinnati (Ohio) e Atlanta (Georgia), e a segunda no Transportation Tecnology Test Center - TTCI), sendo que o pavimento ferroviário continha uma camada de mistura asfáltica aplicada em diferentes espessuras (100 $\mathrm{mm}$ e $200 \mathrm{~mm}$ ), além de uma seção (controle) composta somente por materiais granulares. Esses autores usaram LVDTs, posicionando-os na base do trilho para medir as deflexões. $\mathrm{E}$ os resultados de módulo de via obtidos na segunda linha (TTCI), foram em média de $14 \mathrm{MPa}$ (granular), $20 \mathrm{MPa}$ (com $100 \mathrm{~mm}$ de mistura asfáltica), e 23 $\mathrm{MPa}$ (com $200 \mathrm{~mm}$ de mistura asfáltica).

Já em estudos desenvolvidos por Priest e Powrie (2009), há a proposição de cálculo do módulo de via a partir 
de medidas de deslocamentos com geofones fixados na borda de oito dormentes, mantendo a trafegabilidade normal da ferrovia. Neste trabalho o cálculo foi feito por dois métodos, a saber: i) Displacement basin test (DBT), onde o deslocamento total dos dormentes é obtido através de uma análise de vários pontos em um determinado instante de tempo, a partir de uma carga pontual aplicada; e (ii) Beam on an elastic foundation (BOEF), onde se propõe uma alteração na metodologia que considera a via como uma viga contínua sobre apoios elásticos.

Zakeri e Abbasi (2012) realizaram estudos em cinco segmentos de uma ferrovia em uma região arenosa no deserto do Irã, sendo quatro com diferentes porcentagens de colmatação/contaminação e uma com lastro limpo (seção de controle), uma vez que a colmatação e/ou contaminação do lastro é um fator preponderante na alteração do comportamento mecânico da via permanente e, consequentemente, do módulo de via. Para avaliar esses efeitos em campo, os autores usaram LVDTs instalados na borda de vários dormentes, de modo a medir a deflexão vertical da via em um certo intervalo de tempo, e utilizaram dois tipos de carregamento (trens com carga de 19,8 ton/eixo e máquina de 2 ton/eixo), trafegando a uma velocidade de aproximadamente $15 \mathrm{~km} / \mathrm{h}$. Os resultados de módulo de via situaram-se entre $18 \mathrm{MPa}$ (lastro limpo) e $116 \mathrm{MPa}$ (lastro 62,7\% colmatado/contaminado)

Dentre os estudos realizados no Brasil para determinação do módulo de via em campo, merecem destaque os trabalhos desenvolvidos nas linhas da FLUMITRENS no Rio de Janeiro. Cuconato (1998) montou um dispositivo para medição dos deslocamentos verticais e, posteriormente, Muniz da Silva (2002) e Spada (2003) usaram a viga Benkelman para medição das deflexões geradas pelo carregamento com a passagem de um vagão de teste, em diferentes segmentos e condições de lastro. Além disso, também se destacam os estudos realizados por Fernandes (2005) na Estrada de Ferro Vitória-Minas, ao medir as deflexões geradas igualmente usando a viga Benkelman.

Nos estudos realizados por Muniz da Silva (2002) para determinação do módulo de via, as diferentes condições de lastro foram ensaiadas "in situ" sob carregamento estático (carga por eixo de aproximadamente $200 \mathrm{kN}$ ), usando como metodologia de cálculo do módulo de via, o modelo desenvolvido por Talbot (1918). Os resultados mostraram que nos trechos considerados de boa condição estrutural, os valores de módulo de via de assentamento ficaram entre 6,7 MPa e 63,4 MPa.

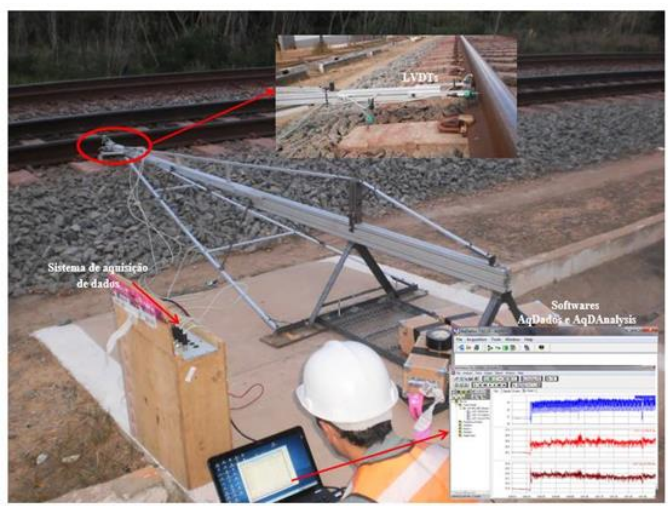

Figura 1. Dispositivo de medição de deslocamentos instalado na EFC

\section{ANÁLISE DE TENSÕES E DETERMINAÇÃO DO MÓDULO DE VIA}

No decorrer do desenvolvimento da presente pesquisa, diversos métodos de análise da via permanente foram avaliados e, devido à simplificação, ampla aplicação e, atual recomendação pela American Railway Engineering and Maintenance-of-way Association (2013), concluiu-se que a abordagem que se vale de apoios contínuos e elásticos sob o trilho é a mais adequada. Dentro deste contexto, o método desenvolvido por Talbot (AREA, 1918), que representa o comportamento da via em função de um carregamento, conforme Equação (1), onde a força é proporcional à deflexão.

Onde:

$$
p=-u y
$$

$\mathrm{p}=$ força por unidade de comprimento $[\mathrm{KN} / \mathrm{m}]$;

$\mathrm{u}=$ módulo de via $[\mathrm{kPa}]$;

$\mathrm{y}=$ deflexão da via $[\mathrm{m}]$.

A Equação diferencial proposta tem como base a hipótese fundamental de Winkler (viga sobre apoio elástico), e é apresentada em (2):

$$
E I \frac{d^{4} y}{d x^{4}}=-u y
$$

Onde:

$\mathrm{E}=$ módulo de elasticidade do trilho $[\mathrm{kPa}]$;

$\mathrm{I}=$ momento de inércia do trilho $\left[\mathrm{m}^{4}\right]$.

A solução da Equação (2), considerando a deflexão da via $y(x)$, a qualquer distância $x$, ao longo do trilho, a partir de um carregamento simples P, é apresentada na Equação (3):

$$
y(x)=\frac{P}{\left(64 \cdot E \cdot I \cdot u^{3}\right)^{1 / 4}} e^{-\lambda x} \cdot(\cos \lambda x+\operatorname{sen} \lambda x)
$$

Onde:

$\mathrm{P}=$ carga da roda $[\mathrm{kN}]$;

$\mathrm{e}=2,7183$ (Neperiano);

$\lambda=\left(\frac{u}{4 E \cdot I}\right)^{1 / 4}=$ fator de amortecimento;

$\mathrm{x}=$ distância para qualquer ponto, a partir do carregamento ao longo do trilho [m].

As sucessivas derivações da Equação da deflexão (3) fornecem a inclinação, o momento fletor, o cisalhamento e

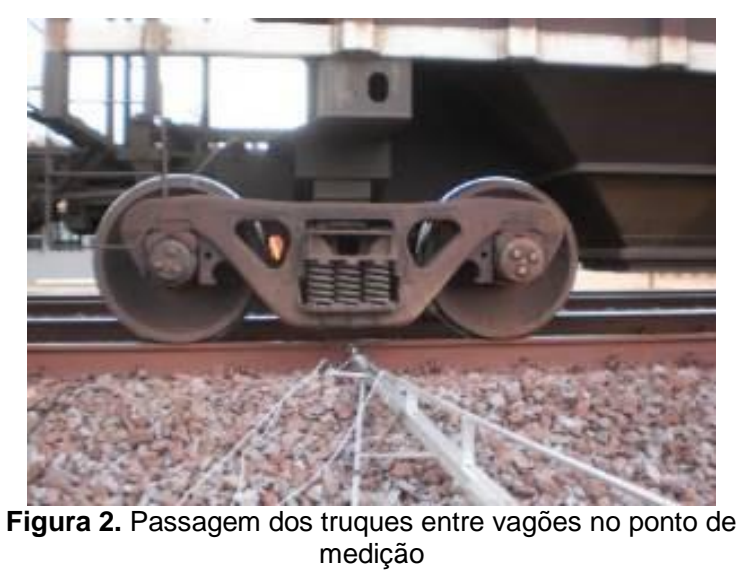


a intensidade do carregamento. A deflexão máxima ocorre no ponto de aplicação do carregamento (debaixo da roda), onde $x=0$. Substituindo $x=0$ em (3), obtêm-se a Equação (4), de deflexão máxima $\left(\mathrm{y}_{0}\right)$ :

$$
y_{0}=\frac{P}{\left(64 E \cdot I \cdot u^{3}\right)^{1 / 4}}
$$

O módulo de via $(u)$ não pode ser determinado através de uma medida direta. Entretanto, pode-se medir a deflexão e, substituindo-se esse valor na Equação (4), obtém o módulo de via, conforme Equação (5):

$$
u=\frac{\left(\frac{P}{y_{0}}\right)^{4 / 3}}{(64 E \cdot I)^{1 / 3}}
$$

Na avaliação dos três diferentes métodos de cálculo do módulo de via vertical apresentados por Zarembski e Choros (1979) (citados anteriormente), esses autores chegaram à conclusão de que a proposição de Talbot (AREA, 1918) se mostrou mais aplicável às medições obtidas em campo, requerendo um número mínimo de valores de deflexão da via.

Segundo Selig e Waters (1994), o módulo de via deve ser calculado a partir de medições das deflexões impostas pelo carregamento no campo, podendo-se calculá-lo basicamente por três maneiras, a partir de dados experimentais, os quais são: i) ensaio de carga pontual (Equação 5); ii) ensaio da bacia de deflexão (Equação 6); e iii) ensaio com veículos de cargas múltiplas (Equação 7).

$$
P=u \cdot A_{y}
$$

Onde:

$A_{y}=$ bacia de deflexão (diferença entre duas deflexões ocasionadas por carregamento leve e pesado) [m].

$$
u=\sum P_{i} / a \sum_{i=1}^{m} y_{i}
$$

Onde:

$P_{i}=$ carga em cada eixo $[\mathrm{KN}]$;

$a=$ espaçamento entre dormentes $[\mathrm{m}]$;

$m=$ número de dormentes;

$y_{i} .=$ deflexão no trilho no iésimo dormente [m].

\section{DESENVOLVIMENTO DO DISPOSITIVO DE MEDIÇÃO E TESTES EM CAMPO}

o Laboratório de Tecnologia de Pavimentação da Escola Politécnica da Universidade de São Paulo (LTPEPUSP) desenvolveu uma primeira versão de dispositivo de medição em 2012, o qual foi utilizado em um levantamento de deslocamentos verticais na Estrada de Ferro VitóriaMinas (EFVM), operada pela Vale (Merheb, 2014). Tratava-se de um "braço" metálico em que era instalado um sensor tipo LVDT em uma das extremidades, o qual ficava apoiado no patim do trilho. O sensor, por sua vez, era conectado a um sistema de aquisição de dados, que registrava os deslocamentos.

Após o aprimoramento da concepção do equipamento, foi desenvolvida uma segunda versão, em 2014-2015 para estudos na Estrada de Ferro de Carajás (EFC). Neste caso, houve um aperfeiçoamento significativo em toda a estrutura, inclusive no que se refere ao comprimento total do braço (esse deveria ser tal, que ficasse fora da área de atuação da carga, ocasionada pela passagem do material rodante, para não interferir na leitura obtida). Para tanto, foram usados perfis de alumínio com elevada rigidez, visando estabilidade entre as hastes de sustentação do braço, principalmente nos pontos de fixação dos LVDTs, os quais poderiam ser instalados em até quatro pontos do braço (por exemplo, um para medição de deslocamento transversal e os outros três para medição de deslocamento vertical).

Neste sistema os LVDTs são posicionados nos locais onde se pretende obter as medidas de deslocamento e, em seguida, faz-se a ligação dos sensores ao sistema de aquisição de dados que, por sua vez, pode ser conectado a qualquer computador usando a interface de rede padrão com protocolo UDP/IP. O computador usado nas medições já deverá estar configurado com os softwares de aquisição (no caso, foi usado o AqDados) e de análise (AqDAnalysis), respectivamente para coleta (cuja frequência pode ser ajustada à velocidade de operação da via) e para análise dos dados. A Figura 1 mostra todo sistema instalado durante a medição de deslocamento em um segmento da EFC.

Como vantagens desse dispositivo de medição podese citar: baixo custo de montagem do sistema, instalação simples, facilidade de utilização em diferentes locais da via por sua mobilidade, além do fato dos deslocamentos poderem ser medidos mantendo a trafegabilidade normal da ferrovia (sem interrupção da operação).

A EFC possui bitola de 1,60 m, trilho TR-68, espaçamento entre dormentes de $0,61 \mathrm{~m}$ e lastro composto de rocha britada. Os segmentos em que foram feitos os levantamentos localizavam-se próximo ao pátio da Vale, em Nova Vida (Maranhão). No local do estudo a ferrovia possui duas linhas com características distintas, a saber: i) linha antiga (em operação desde 1985), com dormente de madeira e lastro colmatado; e ii) linha nova (em operação desde 2013), com dormente de concreto e lastro novo.

\subsection{Teste em menor velocidade sobre lastro colmatado}

O teste em menor velocidade em local com lastro colmatado possuía dormente de madeira e foi realizado com a passagem de vagões tipo hopper fechado (HFT), usados de forma corrente no transporte de grãos, farelo e fertilizantes. Cada vagão deste tipo possui peso médio vazio de 32 ton e capacidade de carga de 98 ton. Nesse teste todos os vagões da composição estavam vazios (i.e, carga de 8 ton/eixo) e os veículos foram reduzindo a velocidade até pararem totalmente no ponto onde estava o dispositivo de medição e depois reiniciarem o movimento novamente, com os LVDTs posicionados no patim do trilho e na borda do dormente, conforme mostra a Figura 2.

Neste caso, foi feita a análise do sinal registrado com o trem ainda em movimento, tanto no momento de frenagem quanto de retomada de velocidade (ambas velocidades menores que $10 \mathrm{~km} / \mathrm{h}$ ). 


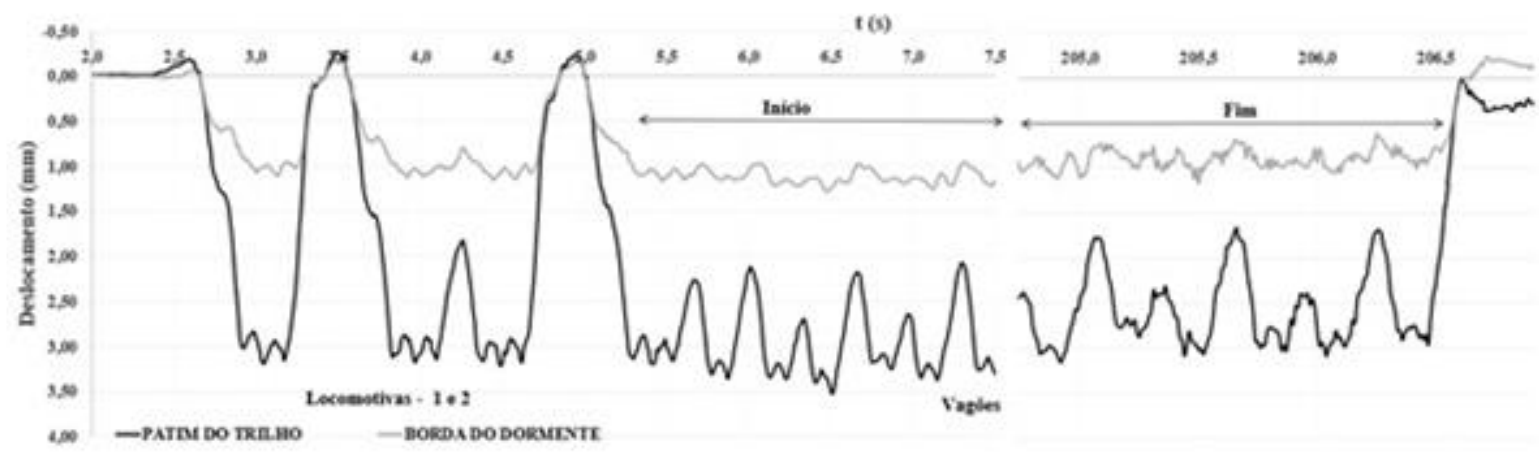

Figura 3. Parte do sinal registrado pela passagem de uma composição de 334 vagões GDT carregados, com registros feitos no patim do trilho e na borda do dormente

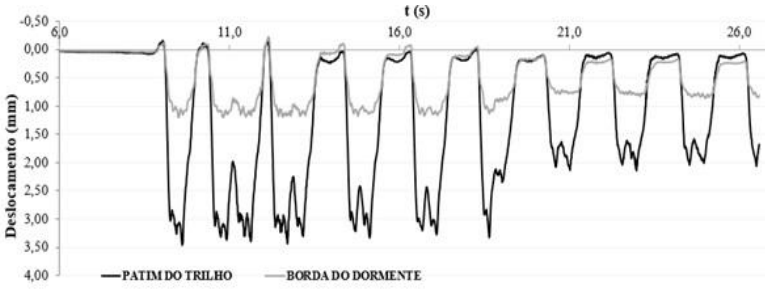

(a) Reduzindo a velocidade (quase parando)

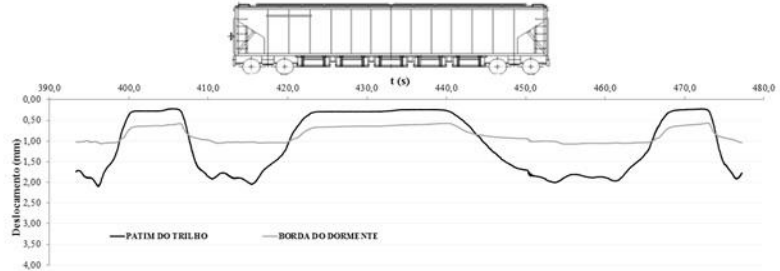

(b) Retomando o movimento

Figura 4. Registro dos deslocamentos em local com lastro colmatado e vagão vazio

\subsection{Teste em operação normal sobre lastro colmatado}

O teste sobre lastro colmatado foi realizado no mesmo ponto do teste anterior, onde se manteve o dispositivo, mas desta vez registrando-se os deslocamentos ocasionados com passagem de um trem carregado com minério de ferro, com velocidade normal de operação (cerca de 60 $\mathrm{km} / \mathrm{h}$ ). A carga de cada vagão foi obtida por meio do histórico da composição fornecido pela Vale, em que o valor médio foi de 31,6 ton/eixo. A título de ilustração, a Figura 3 mostra o sinal registrado pelos LVDTs no patim do trilho e na borda do dormente durante a parte inicial da passagem da composição [até 7,5 s] e depois na parte final [entre 205,0 e 206,5 s]. Destaca-se a diferença de deslocamentos ocorridos quando da passagem das locomotivas em relação aos vagões, com variação expressiva da forma de carregamento.

\subsection{Teste em operação normal sobre lastro novo}

O teste sob operação normal em local com lastro novo possuia dormente de concreto, e as medições de deslocamentos foram realizadas com a passagem de veículos vazios (carga de 5,75 ton/eixo), compostos por vagões tipo GDU, que são usados no transporte de minério de ferro. Esse modelo possui peso médio vazio de 23 ton e capacidade de carga de127 ton.

Neste estudo a intenção era de se realizar medições com o veículo carregado também com minério de ferro (para comparação com a situação anterior), entretanto, por questões logísticas não foi possível seguir com o planejado. Neste caso, só se pôde fazer o levantamento com a passagem de um trem GQT carregado com outros materiais (concentrado de cobre, ferro gusa e brita), composto por 164 vagões. A carga de cada vagão foi obtida por meio do histórico da composição fornecido pela Vale, considerando o modelo transportando concentrado de cobre, em que o valor médio foi de 28,1 ton/eixo.

\subsection{Resultados}

Os resultados das medições realizadas no teste com menor velocidade no local lastro colmatado usando vagões vazios HFT são mostrados nas Figuras 4 (a) registro dos veículos (locomotivas e vagões) reduzindo a velocidade (quase parando) e (b) registro dos veículos retomando o movimento. Os valores médios entre as amplitudes máximas de deslocamento medidas no patim do trilho e na borda do dormente foram de 2,10 $\mathrm{mm}$ e 1,07 $\mathrm{mm}$, respectivamente.

Já as medições com vagões carregados GDT em operação normal são mostradas nas Figuras 5, onde em (a) temse o registro do sinal no patim do trilho e na base do dormente das locomotivas (1 e 2) e de onze vagões e em (b) tem-se a ampliação do sinal para o primeiro e segundo vagão, a uma velocidade de $55 \mathrm{~km} / \mathrm{h}$ (para melhor visualização). Os valores médios entre as amplitudes máximas de deslocamentos medidas no patim do trilho e na borda do dormente foram de $3,50 \mathrm{~mm}$ e $1,18 \mathrm{~mm}$, respectivamente. Vale ressaltar que o pico de deslocamento observado entre os vagões 7 e 8 , é causado pelo impacto da roda, indicando algum tipo de defeito. Ou seja, o dispositivo desenvolvido também é capaz de indicar um possível defeito na roda ou no trilho, podendo igualmente auxiliar no mapeamento deste tipo de patologia.

Já se esperava que, ao aumentar a velocidade dos vagões carregados, as solicitações impostas por eles à via ocasionariam deslocamentos mais elevados, quando comparados com os vagões vazios em menor velocidade, o que é perceptível na Figura 4 e na Figura 5 mostradas anteriormente. Observa-se ainda que o aumento da velocidade faz com que os componentes da estrutura da via sujeitos ao impacto dos eixos de cada vagão se mantenham o tempo inteiro solicitados pela carga da roda, tendo somente um pequeno alívio de deslocamento entre os eixos internos do vagão, intensificando-se entre os truques de dois vagões em sequência. 


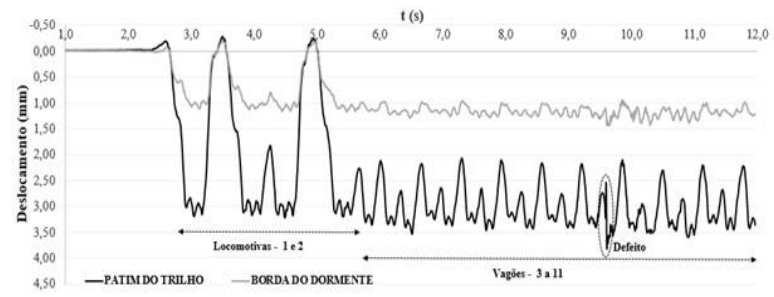

(a) Em velocidade normal de operação

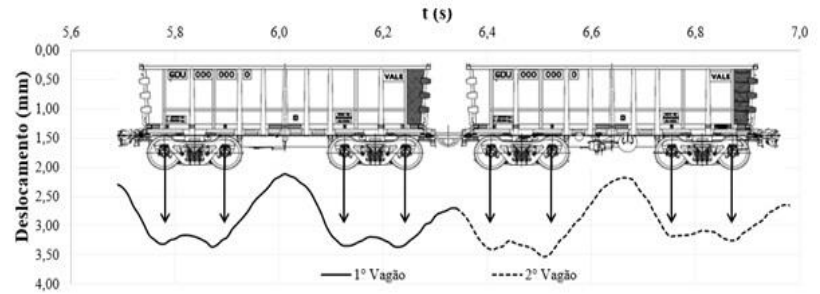

(b) Sinal ampliado do primeiro e segundo vagão

Figura 5. Registro dos deslocamentos em local com lastro colmatado e vagão carregado

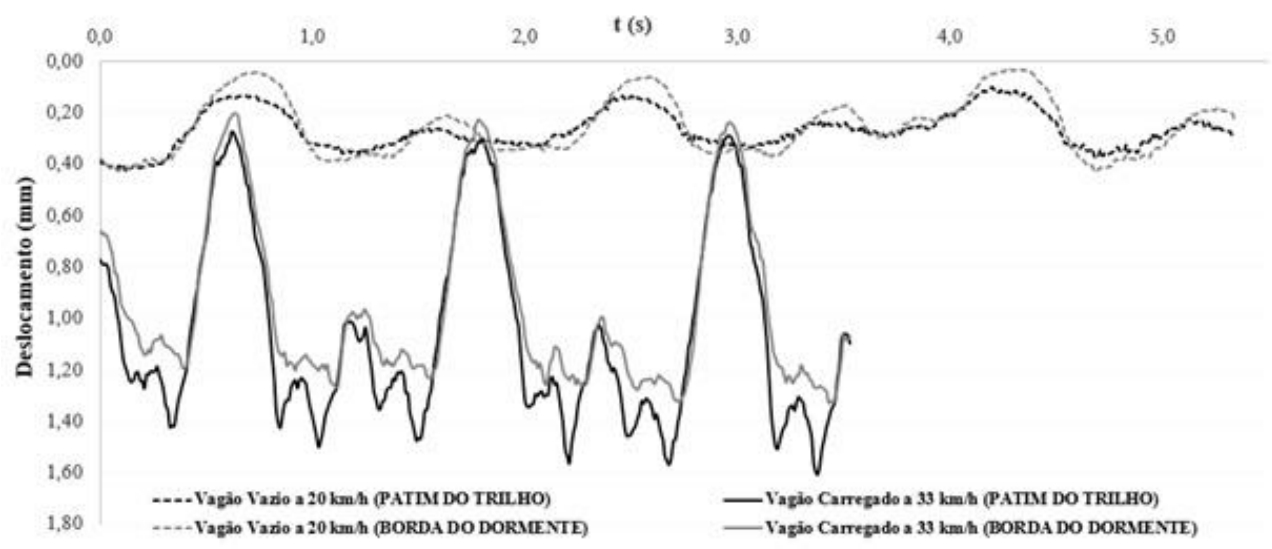

Figura 6. Registro dos deslocamentos em local com lastro novo e dormente de concreto

Entretanto, a mesma afirmação não é válida para o carregamento em menor velocidade, onde o alívio de deslocamento é maior e, além disso, a carga das rodas entre truques de dois vagões subsequentes geram praticamente as mesmas amplitudes de deslocamentos, mostrando que o impacto da carga na via permanente se deve à somatória desse conjunto.

Já na condição de lastro novo e dormente de concreto, pelo fato das amplitudes de deslocamentos terem sido muito parecidas em cada situação, ainda que solicitadas por diferentes modelos de vagões, é mostrado na Figura 6, os resultados das medições realizadas com a passagem de vagões GDU (vazios) e GQT (carregados), a $20 \mathrm{~km} / \mathrm{h}$ e $33 \mathrm{~km} / \mathrm{h}$, respectivamente.

Verifica-se que à medida que a via foi solicitada pelos vagões vazios, os valores médios de amplitudes máximas de deslocamentos gerados no patim do trilho e na borda do dormente foram muito parecidas, aproximadamente 0,37 mm em ambos. Já com vagões carregados, os valores médios entre as amplitudes máximas de deslocamentos medidas no patim do trilho e na borda do dormente foram de cerca de 1,57 mm e 1,25 mm, respectivamente. Ao comparar ambos os carregamentos solicitando a via com diferentes velocidades fica evidente a diferença que há entre os valores médios de amplitudes de deslocamentos gerados no patim do trilho, entretanto, o mais importante a se notar aqui é que, ao aumentar a velocidade, há diminuição do repouso entre truques, elevando o impacto gerado por cada roda na via.

As medições realizadas no local com lastro colmatado e dormente de madeira, com a passagem de vagão vazio foram $96 \%$ superiores no patim do trilho em relação ao levantamento feito na borda do dormente. Já com o vagão carregado, os deslocamentos no patim do trilho passaram a ser $197 \%$ superiores aos da borda do dormente. Como já esperado, isso confirma que os deslocamentos são mais elevados ao se posicionar o LVDT próximo ao ponto de aplicação da carga (região mais solicitada), sendo mais adequado, do que medir na borda do dormente.
Por fim, com os valores das cargas que ocasionaram os maiores valores de deslocamentos em cada condição de lastro (colmatado e novo), e definição de uma metodologia de cálculo, pode-se determinar o módulo de via. E nesse estudo para determinação de tal parâmetro nos dois segmentos da EFC avaliados, adotou-se o modelo apresentado na Equação (5), em que se obteve os resultados de $20 \mathrm{MPa}$ (colmatado) e $50 \mathrm{MPa}$ (novo).

\section{CONCLUSÃO}

O dispositivo de medição de deslocamentos em via permanente desenvolvido nessa pesquisa, cujos resultados podem ser usados posteriormente na determinação do módulo de via, se mostrou prático e eficiente na obtenção de dados in situ, possibilitando a leitura dos deslocamentos verticais no patim do trilho e na borda do dormente com a passagem de vagões vazios e carregados sem interrupção da operação. A forma de sinal registrada demonstra a validade dos deslocamentos, pois confere com os de estudos apresentados na literatura.

As medições de deslocamento no lastro novo e dormente de concreto com o vagão vazio mostraram que praticamente não há diferenças em se realizar a medida no patim do trilho ou na borda do dormente, ocorrendo somente um pequeno aumento com o vagão carregado. E nessa situação, os valores médios de deslocamentos estão próximos do limite estabelecido por Talbot (AREA, 1918) para uma via em condições normais de operação (que é de 1,63 mm). Vale ressaltar, que a diferença de rigidez que há entre dormentes (concreto e madeira), e a forma como cada um dissipam as tensões no lastro, implica em diferentes amplitudes de deslocamento.

Evidenciou que, ao se realizar medições de deslocamento com o trem em movimento (não de maneira estática) e com o uso de LVDTs posicionados no patim do trilho e na borda do dormente, as amplitudes dos valores são diferentes, aumentando significativamente quando o lastro se 
encontra colmatado. Neste caso, concluiu-se que as medidas efetuadas no patim do trilho (região mais solicitada) são mais adequadas do que se realizadas na borda do dormente.

Adicionalmente, o dispositivo também demonstrou que pode eventualmente ser capaz de indicar um possível defeito na roda ou no trilho, podendo igualmente auxiliar na indicação de ocorrência deste tipo de patologia.

O dispositivo de medição tem baixo custo para montagem do sistema, é de instalação simples e possui facilidade de uso em diferentes locais da via devido à sua mobilidade, além de permitir a análise rápida de dados, podendose trabalhar sem interrupção da operação. Por fim, demonstra ser uma ferramenta útil para auxiliar a gerência de manutenção ferroviária.

\section{AGRADECIMENTOS}

À Vale S.A. pela parceria em projetos de pesquisa e à equipe de manutenção da via permanente da Estrada de Ferro Carajás.

\section{REFERÊNCIAS}

American Railway Engineering Association - AREA (1918) First Progress Report of the Special Committee on Stresses in Railroad Track. In: Bulletin of American Railway Engineering Association vol. 19, pp. 875-1058.

American Railway Engineering and Maintenance of Way Association - AREMA. Manual for Railway Engineering. Vol. 1 a 4. 2013 .

Anderson, J. S.; Rose, J. G. (2008) In-Situ Test Measurement Techniques within Railway Track Structures. Joint Rail Conference, Wilmington, Delaware, USA, pp. 187-207. DOI: 10.1115/JRC2008-63047.

Cai, Z.; Raymond, G. P.; Bathurst, R. J. Estimate of Static Track Modulus Using Elastic Foundation Models. Transportation Research Board 1470. Washington, D. C., p. 65-72. 1994.

Cuconato, J. M. (1998) Estudo da Contaminação do Lastro Ferroviário e o Uso de Geossintéticos no Controle do Fenômeno. Dissertação de mestrado, COPPE/UFRJ, RJ, 110p.

Esveld, C. (2001) Modern Railway Track, 2nd Editon. Delft University of Technology.

Fernandes, G. (2005) Comportamento de Estruturas de Pavimentos Ferroviários com Utilização de Solos Finos e/ou Resíduos de Mineração de Ferro Associados a Geossintéticos. Tese de Doutorado, Universidade de Brasília, Brasília, DF, 253p.

Indraratna, B., Salim, W., Rujikiatkamjorn, C. In: Advanced Rail Geotechnology Ballasted Track, Taylor \& Francis Group, London, UK, 2011.

Kerr, A. D. (1983), A Method for Determining the Track Modulus Using a Locomotive or Car on Multi-Axle Trucks. In: Bulletin of American Railway Engineering Association 692, vol. 84, pp. 269-286.

Lundgren, J. R., Martin, G. C., Hay, W. W. A Simulation Model of Ballast Support and the Modulus of Track Elasticity.

Transportation Series $N^{\circ} 4$. University of Illinois Urbana, Illinois, September, 1970, 111p.
Merheb, A. H. M. (2014) Análise Mecânica do Lastro Ferroviário por Meio de Ensaios Triaxiais Cíclicos. Dissertação de mestrado, USP, SP, 148p.

Priest, J. A., Powrie, W. (2009) Determination of Dynamic Track Modulus from Measurement of Track Velocity During Train Passage. Journal of Geotechnical and Geoenvironmental Engineering, 135, (11), 1732-1740.

DOI:10.161.(ASCE)GT.1943-5606.0000130.

Selig, E. T., Waters, J. M., (1994) Track Geotechnology and Substructures Management. Thomas Telford Services Ltd., Londres, 446p.

Selig, E. T., Li, D. Track Modulus: Its Meaning and Factors Influencing It. Transportation Research Board 1470. Washington, D. C., p. 47-54. 1994.

Silva, L. F. M. (2002). Fundamentos Teórico-Experimentais da Mecânica dos Pavimentos Ferroviários e Esboço de um Sistema de Gerência Aplicado à Manutenção da Via Permanente. Tese de Doutorado. COPPE/UFRJ, RJ, 333p.

Spada, J. L. G. (2003) Uma Abordagem de Mecânica dos Pavimentos Aplicada ao Entendimento do Mecanismo de Comportamento Tensão-Deformação da Via Férrea. Tese de Doutorado, COPPE/UFRJ, RJ, 240p.

Zakeri, A. J., Abbasi, R. (2012) Field Investigation on Variation of Rail Modulus in Ballasted Railway Tracks. Latin American Journal of Solids and Structures vol. 9. DOI: 10.1590/S167978252012000600002 .

Zarembski, A. M. e Choros, J. (1979) "On the Measurement and Calculation of Vertical Track Modulus" In: Proceedings AREA, Bulletin 675, vol.81, pp. 157-173. 